\title{
El poder como termino transversal en la Ideología Alemana Clasificaciones y relecturas.
}

\author{
Power as a cross-sectional term in German ideology. \\ Classifications and recreadings.
}

\author{
Por: Brenda Flavia Araceli Ojeda * \\ Universidad Nacional del Nordeste \\ E-mail: Brendaflaviaaraceliojeda@gmail.com
}

Fecha de recepción: 16/03/2021

Fecha de aprobación: 25/04/2021

DOI: http://dx.doi.org/10.30972/ach.065604

\section{Resumen}

El presente artículo pretende señalar las posibles referencias sobre el término poder en la obra La Ideología Alemana, escrita en conjunto por el filósofo Karl Marx y Friedrich Engels. Mediante, tal exposición, se espera realizar una clasificación y explicación de los diferentes poderes qué están implícitos o se muestran en la obra.

El abordaje de dichas nociones se lleva a cabo, a partir de la concepción materialista e histórica que introducen Marx-Engels en la correspondiente concepción filosófica. Es de suma importancia comprender en que consiste la perspectiva en la cual se posicionan los autores, ya que la historia como la materialidad -con su respectivo método dialectico- fundamentan la realidad concreta y al ser del individuo existente.

Palabras claves Poder, Materialismo- Histórico, División del trabajo, Fuerzas productivas, Ideología Alemana.

\footnotetext{
* El siguiente trabajo de investigación se llevó a cabo en el contexto de la cátedra Seminario I: Análisis de una obra filosófica del año 2020. Agradecimiento a Navarro ${ }_{2}$ Cosme por el acompañamiento y aportes sobre el tema.

${ }^{*}$ Estudiantx del Profesorado en Filosofía de la Facultad de Humanidades (UNNE)
} 


\section{Abstract}

This article aims to point out the possible references to the term power in the work The German Ideology, written jointly by the philosopher Karl Marx and Friedrich Engels. Through such an exposition, it is expected to make a classification and explanation of the different powers that are implicit or shown in the work. The approach to these notions is carried out, starting from the materialist and historical conception introduced by Marx-Engels in the corresponding philosophical conception. It is of utmost importance to understand what the perspective in which the authors are positioned consists of, since history as materiality - with its respective dialectical method - base the concrete reality and the being of the existing individual.

Key words: Power, Historical Materialism, Division of labor, Productive forces, German Ideology.

\section{Cómo citar este artículo:}

APA: Ojeda Araceli, B. F. (2021). El poder como termino transversal en la Ideología Alemana Clasificaciones y relecturas. Acheronta, № 6, 125-149. Recuperado de: (agregar dirección web)

\section{Introducción}

El presente trabajo tiene por tema la cuestión sobre las nociones de poder expuestas por Marx-Engels en la Ideología Alemana. La importancia de su elección reside en el vasto e histórico debate que supone la definición y función del poder entre los filósofos anteriores y contemporáneos a los autores mencionados.

Las investigaciones llevadas a cabo por diversas disciplinas, nos muestran la amplitud de su campo de estudio. Tal afirmación puede comprobarse en ciencias como la Sociología y Ciencias Políticas, en las cuales se han delimitado la significación de poder, objeto de estudio y la pertinencia particular en cada ámbito disciplinar.

Así pues, que la concepción sobre el poder sea objeto de indagación en 
distintas ciencias nos advierte que su abordaje posee tres características esenciales: en primer lugar, no es una problemática o temática acabada ni cerrada; en segundo lugar, es posible encontrarse con multiplicidad de perspectivas relacionadas o que divergen entre sí; y por último, la riqueza conceptual mantiene vigencia.

Uno de los máximos exponentes del tema es Friedrich Nietzsche, quien en la obra la Mas allá del Bien y del Mal (1983), identifica al poder con la voluntad, en otras palabras, considera que el mundo es voluntad de poder y esto indica o significa que lo real es un conjunto de fuerzas que se producen de manera desigual, y su cualidad instintiva implica que cada fuerza sea distinta entre sí. Lo curioso de estas fuerzas es que intentan dominar o son dominadas por otras fuerzas, lo que se convierte o deviene en una lucha de instintos constante.

Otro filósofo que analiza la problemática es Russell Bertrand, quien en su texto El poder en los hombres y en los pueblos (1953), define al poder, como la producción de los efectos deseados, y a diferencia de Nietzsche este adquiere un carácter cuantitativo, en tanto el sujeto obtiene poder si consigue la mayoría de los efectos que desea. Según el autor hay varias maneras de clasificar los poderes y los diferencia su utilidad.

Ahora bien, el tratamiento del trabajo se efectuará teniendo como texto de base y primordial: La ideología alemana (2010), obra escrita conjuntamente por el filósofo alemán Karl Marx y Friedrich Engels; como texto complementario Marx, Engels y el Marxismo (1947) del autor V. I. Lenin; y Nota a la edición alemana (1974) escrita por Friedrich Engels.

Ateniéndonos al tema seleccionado, se puede señalar que los autores MarxEngels no aportan una especificidad en torno a cómo funciona el poder o cómo se relacionan los poderes entre sí. Demás está decir, que la falta de sistematización provoca que los apartados que brindan, describiendo algunas cualidades del poder, resulten vagos y dispersos, lo cual dificulta comprender de qué manera se conquista el poder político en manos del proletariado o sociedad civil, siendo éste el ideal y propósito fundamental de la Ideología Alemana.

Frente a esta insuficiencia teórica es donde reside nuestro problema de 
Abril 2021.

ISSN 2344-9934

investigación y, por el cual, procedemos a enunciar las siguientes preguntas que se intentará responder: ¿En qué o cómo se diferencia cada poder? ¿Se transfiere? ¿De qué manera? ¿Cuáles son las acepciones que aparecen o pueden conjeturarse? ¿Qué es el poder en Marx? ¿Quién detenta el poder? ¿Quiénes son los que poseen y quienes los desposeídos?

Aunque es notable que el objetivo de los autores no reside en analizar o precisar de qué hablamos cuando nos referimos al poder en cuanto tal; se puede decir que los planteos de este sistema filosófico han influenciado y servido como herramientas contundentes para reconstruir una interpretación y definición de poder. Enmarcando tal concepto en distintas posiciones o creando nuevas perspectivas, como es el caso de Michel Foucault y Louis Althusser.

En este sentido, se intentará demostrar que estamos frente una concepción plural del poder, que depende en absoluto de los seres sociales actuantes. Vínculos que se complejizan de acuerdo al grado de intervención en el poder económico y político. Siendo el efecto que posee la producción en la vida material, un elemento secundario o como consecuencia de estas relaciones.

Por otro lado, la monografía cuenta, en principio con un desarrollo, en donde se introducirá ciertos conceptos que resultan centrales para comprender el posicionamiento de Marx, la relación estrecha que guarda con los poderes y para el esclarecimiento del trabajo se intentará responder: ¿en qué consiste la dialéctica materialista? ¿Qué es la división de trabajo? ¿Qué o quienes son las fuerzas productivas?

En el segundo tramo, se nombrarán las distintas nociones que aparecen en la obra, de las cuales se pretende explicar: ¿Qué es el poder individual? ¿Qué es el poder social? ¿Cuál es su importancia? ¿Qué es el poder político y económico?

Se brindará una definición aproximada de lo que se comprende por poder a partir de la reconstrucción conceptual que se lleve adelante.

Por último, constará de una conclusión en donde se plasmen ciertas reflexiones, se ajusten criterios que han quedado sin profundizar y se exponga una posición afirmativa o crítica frente a la problemática. 
En tanto, el objetivo general es ofrecer una definición clara y comprensiva sobre el concepto de poder en Marx, para lo cual es necesario, identificar minuciosamente en qué momentos lo menciona y enfocarnos en el marco en que es designado. Y a su vez, mostrar las diferentes nociones, detallar características y funciones de cada poder.

\section{Definiciones que esclarecen el desarrollo del tema}

\section{2. a. La dialéctica materialista, método innovador}

Para iniciar el desarrollo del trabajo se procederá a exponer ciertas apreciaciones contextuales, en particular, la que concierne al pensamiento marxiano, ya que nos permitirá comprender cómo se introduce la concepción materialista y el método dialectico al sistema filosófico de Marx-Engels.

Dicho esto, el siglo XIX, se caracterizó, entre tantas razones, por el predominio de tres corrientes ideológicas, las cuales, se originaron en tres países reconocidos por sus grandes avances científicos, a saber: la filosofía clásica alemana, la economía política inglesa y el socialismo francés. Marx inmerso en esta coyuntura intelectual, política y económica decide continuar y superar críticamente tales corrientes de pensamientos que a sus modos fundaban la realidad.

En 1844-1845, influenciado por la doctrina materialista de Ludwig Feuerbach adopta esta posición filosófica, pero al poco tiempo la desacredita por considerarla insuficiente. De él retoma la importancia de una historia-universal y la contraposición a la doctrina idealista de Hegel (que en ese momento implicaba luchar contra las instituciones políticas, religiosas y jurídicas).

El materialismo en su sentido más básico refiere al mundo natural en sí, a lo que nos rodea, nuestro entorno y de lo que nosotros mismos estamos compuestos, es decir, nuestra corporalidad. Marx-Engels en oposición al idealismo hegeliano consideran que la Historia, ciencia que estudia los procesos y hechos 
que acontecen en un lugar determinado, ha producido sus ideas eludiendo los hechos materiales y concretos que prevalecieron desde tiempos remotos.

Por la separación entre el trabajo físico e intelectual, la Historia y en especial la Filosofía, enaltecieron la conciencia y su saber, distanciándose de lo real y concreto, formulando teorías completamente abstractas. Partiendo desde el espíritu del ser humano, es decir, su conciencia pura pretendían explicar el avance de este.

Marx-Engels (2010), quienes analizan este tipo de historiografía explican que "la transformación de la historia en historia universal no constituye, ni mucho menos, un simple hecho abstracto de la "autoconciencia" del espíritu universal o de cualquier otro espectro metafísico, sino un hecho perfectamente material y empíricamente comprobable" (p.50).

Por tanto, partiendo de este posicionamiento la historia es concebida como aquellas sucesiones materiales que dan cuenta del proceso productivo del ser humano que antecede a una determinada época como la realidad misma. Se trata de una historia empíricamente comprobable en tanto, estos procesos productivos se concreten en el intercambio productivo o comercial, los cuales, al tener un alcance no sólo local las consecuencias de estas interacciones -productivasimplican una transformación global, es decir, constituyen una historia material y universal. Dicho esto, la concepción materialista de la historia implica:

[...] hacer concordar la ciencia de la sociedad con la base materialista y reconstruirla con arreglo a esta base. Si el materialismo en general explica la conciencia como derivado de la existencia, y no al revés, su aplicación a la vida social de la humanidad exige que la conciencia social se explique cómo derivado de la existencia social (Lenin, 1947, p.19).

Así pues, esta conciencia social que tiene su origen y surge de la existencia social, refiere a los modos de producción social, porque cabe recordar que Marx-Engels sostienen que el ser es, y reafirma su existencia, de acuerdo a lo que hace, es decir, en tanto, produce según las condiciones materiales de las que se halle previsto y, en consecuencia, cada acción o trabajo realizado por el hombre cobra significado y es 
reconocido en sociedad. Esta praxis social, en donde se procura elaborar o buscar los medios para satisfacer necesidades, es un dato empírico- histórico. Por lo tanto, el materialismo histórico es la incesante aplicación del materialismo al campo de los fenómenos sociales.

En este sentido, la propia individualidad es descripta y comprendida en un plano histórico y material. A partir de esta concepción el ser debe ser estudiado desde un entronque fundamentalmente social, inmersos en relaciones de producción y, que no evidencian puras especulaciones sobre un cogito universal que predomina por sobre la vida real y concreta. En palabras de Marx-Engels:

Se manifiesta, por tanto, ya de antemano, una conexión materialista de los hombres entre sí, condicionada por las necesidades y el modo de producción y que es tan vieja como los hombres mismos; conexión que adopta constantemente nuevas formas y que ofrece, por consiguiente, una "historia", aun sin que exista cualquier absurdo político o religioso que también mantenga unidos a los hombres (MarxEngels, 2010, p.31).

Hasta el momento se describió brevemente en que consiste el materialismo y el concepto de historia que Marx-Engels resignifican desplazando tanto al materialismo como a la historia al terreno de la vida y naturaleza concreta, a la constitución del individuo y la producción. La importancia que supone la introducción de estos, es que resultan ser dos componentes imprescindibles que integran el método dialectico, el cual se intentará explicar.

La dialéctica como método tiene sus precedentes en la antigüedad con Platón, quien lo empleaba como elemento refutatorio de ideas que se contraponían. Luego de este se reconoce en el filósofo alemán Hegel, Georg. W. F, la profundización y un análisis llevado a su máxima expresión y limites, denominándolo dialéctica idealista.

Marx siendo, en su periodo de estudiante, un fiel adepto al hegelianismo de izquierda conoce las concepciones de su maestro, y al romper con la doctrina hegemónica, adopta la dialéctica como método.

Pese a concebir la dialéctica como método, su gran aporte es haberlo invertido, es decir, no teoriza a partir de la especulación pura ni del individuo en sí, 
Abril 2021.

sino que la base de este método es material e histórica, en relación a las luchas sociales. Desde esta perspectiva es donde parte para explicar la realidad externa concreta, sin perder de vista los fenómenos sociales. Por tanto, "Marx y Engels consideraban la dialéctica hegeliana, por ser la teoría del desarrollo más unilateral, rica en contenido y profunda, como la más grande conquista de la filosofía clásica alemana" (Lenin, 1947, p. 17).

En otros términos, la dialéctica es la ciencia que parte de las generalidades del movimiento, desarrollo de los procesos tanto del mundo natural como del pensamiento del ser humano.

La dialéctica inscripta en una base material e histórica, nos permite analizar las contradicciones, las relaciones de producción que se establecen y establecieron históricamente las clases que detentan determinada época. Nos brinda empíricamente los datos que integran las distintas fases del desarrollo productivo, además de develar de manera consciente las prácticas y luchas que son dadas y surgieron por el devenir mismo. La implicancia de la dialéctica materialista en el mundo y la naturaleza contribuye a comprender que aquellos, se componen de hechos y procesos que constantemente están resignificándose o mutando, no es acabado ni su historia es lineal.

\section{2. b. División del trabajo}

Siguiendo con las apreciaciones que esclarezcan el presente trabajo, en este punto se expondrá de manera breve que es la división de trabajo y la correspondiente importancia.

Así pues, el posible origen de la división de trabajo puede hallarse en las sociedades que se abastecían del cultivo y su modo de producción se basaba en la agricultura. Por su modo de producción en esta etapa la organización social es denominada agraria o agrícola, y debido al avance y necesidad del comercio, de los artesanos y una base militar que proteja, surge la división de trabajo.

En este sentido, la división de trabajo refiere a la especificidad o especialización 
del trabajo, el cual, consiste en la segmentación y asignación de diferentes tareas, funciones y labores -a un grupo de trabajadores o a una serie de sujetos- que parezcan necesarias para la producción de un bien material determinado. Para ello, se tiene presente la fuerza física, capacidad o lo que el individuo-grupo sabe hacer, es decir, las habilidades y recursos que posean. Lo negativo de esta radica en dos razones, por un lado, la continua repetición que conllevan los trabajos termina por despersonalizar al trabajador, y por el otro, este mecanicismo requiere de un menor esfuerzo intelectual o se precisa de menor conocimiento para el desarrollo de su trabajo. En consecuencia, ante el poco empleo de las facultades cognoscitivas, el empleado se encuentra en una posición de desventaja, es decir, menos calificado ante las actividades productivas que aspire llegar.

Marx-Engels afirman que la división de trabajo proviene de una relación de dependencia por cuestiones jerárquicas y de esto modo logra establecer un control social; solo en el sistema comunista la división de trabajo tendría su salvedad, ya que dicho sistema anula las jerarquías entre los individuos o grupos mismos.

En palabras de Marx-Engels (2010):

En efecto, a partir del momento en que comienza a dividirse el trabajo, cada cual se mueve en un determinado círculo exclusivo de actividades, que le es impuesto y del que no puede salirse; el hombre es cazador, pescador, pastor o crítico crítico, y no tiene más remedio que seguirlo siendo, si no quiere verse privado de los medios de vida; al paso que en la sociedad comunista, donde cada individuo no tiene acotado un círculo exclusivo de actividades, sino que puede desarrollar sus aptitudes en la rama que mejor le parezca, la sociedad se encarga de regular la producción general, con lo que hace cabalmente posible que yo pueda dedicarme hoy a esto y mañana a aquello, que pueda por la mañana cazar, (...) sin necesidad de ser exclusivamente cazador, pescador, pastor o crítico, según los casos (p. 34).

\section{2. c. Fuerzas Productivas}


De acuerdo al posicionamiento de Marx-Engels las fuerzas productivas conforman junto a las relaciones sociales, los modos de producción, es decir, que tal concepción es descripta en función de la economía e historia y la acción social.

Por ser parte de los modos de producción según los autores las fuerzas productivas reflejan el poder real de trabajo, con determinados medios de producción y dentro de una forma definida de cooperación social los seres humanos producen los medios materiales para satisfacer sus necesidades básicas y complementarias.

De acuerdo a esto, las fuerzas productivas refieren a todo instrumento, maquinaria, herramienta y técnica que se emplea en la elaboración de un producto, adquiriendo sentido cuando se incorpora y son ejercidos u operados por la fuerza física del ser humano.

Gracias a las fuerzas productivas se posibilita tanto el progreso de la técnica y de la ciencia, como el impulso y avance de las fuerzas sociales creadas por la cooperación y la división del trabajo. Es por esta razón que el desarrollo de las fuerzas productivas consiste en el aumento de la productividad del trabajo o, dicho en otros términos, la finalidad de esta radica en que la sociedad pueda producir la misma cantidad de bienes con una menor cantidad de trabajo.

Otro punto a destacar sobre el desarrollo de las fuerzas productivas es su carácter de necesidad o necesario en relación a la calidad de vida material de las personas en general, ya que su buen desarrollo posibilita que el intercambio productivo mantenga estable el mercado global y con esto, se previene insuficiencias en la producción. Así pues:

Este desarrollo de las fuerzas productivas (que entraña ya, al mismo tiempo, una existencia empírica dada en un plano histórico-universal, y no en la vida puramente local de los hombres) constituye también una premisa práctica absolutamente necesaria, porque sin ella sólo se generalizaría la escasez y, por tanto, con la pobreza, comenzaría de nuevo, a la par, la lucha por lo indispensable y se recaería necesariamente en toda la inmundicia anterior; $y$, además, porque sólo este desarrollo universal de las fuerzas productivas lleva consigo un intercambio universal de los hombres (Marx-Engels, 2010, p.36). 


\section{Acepciones en torno a la concepción de poder ${ }^{1}$}

Como puede observarse en la obra la Ideología alemana (2010), la concepción sobre el poder no es problematizada por Marx-Engels, y aunque no se detengan a abordar la definición del término, el mismo, es empleado y designado en cuestiones muy relevantes que conforman el interés y núcleo de la obra.

Se considera que temas como la cuestión social, política y económica, desarrollados a lo largo de la obra, aluden cada uno a un tipo de poder, y además, tales temas son fundamentales para comprender dialécticamente las relaciones 0 actividades de producción que predominan material e históricamente en el mundo en general, y en particular, entre los individuos y por fuera de ellos. Por tanto, como se mencionó en la introducción en este punto se intentará responder: ¿Cuáles son las acepciones que aparecen o pueden conjeturarse? ¿Qué es el poder? ¿Quién detenta el poder? ¿Quiénes son los que poseen y quienes los desposeídos?

Por consiguiente, en este apartado se pretende mencionar y explicar cada aspecto que hace al poder un conjunto de fuerzas y relaciones, fundado en tres elementos, como son los fenómenos económicos, los procesos históricos y la materialidad.

La primera distinción que podríamos señalar es el poder del individuo. Si bien, esta categoría no está explicita en el autor, lo mencionamos como un primer momento o instancia que constituye al poder.

En este sentido, antes de explicar las diferentes fases del desarrollo de la organización social y en contraposición al sistema idealista, Marx-Engels partiendo de la mencionada posición materialista, aportan una serie de afirmaciones que definen y constituyen al ser del individuo. Así pues, siguiendo la línea de este pensamiento, el ser es en tanto hace y lo que hace esta en relación con lo que produce para subsistir. Tanto el sujeto como su praxis están dotados de materia por lo que es innegable empíricamente que la existencia y vida del ser humano no esté ligada a su actividad

\footnotetext{
${ }^{1}$ Como la explicación sobre la noción de poder se centra exclusivamente en la obra La Ideología Alemana resulta pertinente advertir que es posible encontrarse en otras obras de Marx o Engels, que el planteamiento o al menos una descripción sobre el tema propuesto se pudo profundizar y desarollar.
} 
Abril 2021.

ISSN 2344-9934

como a la materia. En palabras de Marx-Engels (2010), "lo que son coincide, por consiguiente, con su producción, tanto con lo que producen como con el modo cómo producen. Lo que los individuos son depende, por tanto, de las condiciones materiales de su producción" (p. 19).

En consecuencia, esta clase de poder se encuentra relacionada con la acción del individuo. No obstante, cabe destacar que, este poder-hacer se establece o configura en la acción o actividad que conlleva la producción, la cual, se evidencia principalmente en el momento de elaborar los instrumentos y sus respectivas técnicas, que modifican directamente algo de la realidad concreta y, de manera indirecta, satisface las necesidades básicas del ser.

Aquella etapa, referida a la praxis individual conforma el primer hecho histórico, es decir, "la producción de la vida material misma" (Marx-Engels, 2010, p. 40). En esta fase histórica la organización social se caracteriza por ser comunitaria y la división de trabajo se muestra escueta. Si bien, partimos desde el punto de vista del individuo concreto, cabe agregar que no se trata de una actividad productiva de por sí y para sí mismo, sino que justamente dichas actividades se llevan a cabo en sociedad.

Lo evidente en este primer momento es que la naturaleza se presenta imponente ante el ser humano, y frente a la inmensidad y poco control sobre la misma coexiste al respecto una especie de alienación hacia ella, es decir, esta primera etapa de la organización social se caracteriza por la alienación o sensación de extrañeza que existe en la relación entre el ser humano y la naturaleza. Como hacen referencia los autores sobre este aspecto, "la conciencia de la naturaleza, que al principio se enfrenta al hombre como un poder absolutamente extraño, omnipotente e inexpugnable" (Marx-Engels, 2010, p.31).

En este marco, alienación y poder se irán desplazando y complejizando según el desarrollo de múltiples factores -económicos, políticos, jurídicos-, y cualidades internas y externas al trabajo, producción, etc.-, que conforman las circunstancias o realidad material de una sociedad. Por lo tanto, en esta instancia la naturaleza ejerce sobre el ser, cierto poder que lo doblega, lo cual deriva en una relación alienada, ya que como se mencionó, en esta primera instancia el poder representa "la naturaleza 
que no ha sufrido aún ninguna modificación histórica" (Marx-Engels, 2010, p.32). ${ }^{2}$

Además, se puede afirmar, que este tipo de poder individual se caracteriza por la capacidad misma de trabajar, crear, y construir según las condiciones materiales y en simultáneo, generar la conciencia del sujeto. Por tanto, este poder definido por la acción -productiva- es inherente al ser y no es acabada sino que en la medida en que surjan nuevos desarrollos, sucesos, entre otras cuestiones, irá transformándose.

Con respecto a la conciencia, es preciso agregar que, las actividades o intercambios productivos que realiza el individuo traen aparejado, al mismo tiempo, la producción y contenido de la conciencia del sujeto y dado que hasta el momento los medios para satisfacer necesidades no se fabrican en solitariedad, se torna consciente la relación (necesaria) con la sociedad.

Por tanto según los autores, "esta conciencia gregaria o tribual se desarrolla y perfecciona después, al aumentar la producción, al acrecentarse las necesidades y al multiplicarse la población" (Marx-Engels, 2010, p.32).

Así pues, siguiendo en la misma línea, podemos dar lugar a la segunda forma de poder, es decir, el poder social.

Para este tema en particular, será necesario brindar ciertas características que Marx-Engels presentan de la sociedad moderna o, dicho de otro modo, la que se constituye en la cuarta fase del despliegue histórico, ya que contribuye a delimitar y comprender el foco de la cuestión.

A grandes rasgos, se sostiene, que la producción en fases anteriores supone un intercambio comercial comunitario o concentrado en el poder monárquico (mediante trueques o con alcances exclusivamente locales), y la división del trabajo como la propiedad privada es prácticamente nula. Tal forma de interacción comercial y política, cambia de manera paulatina pero completamente en la cuarta fase, ya que ocurren ciertas transformaciones que afectan radicalmente la realidad concreta. Siendo así,

\footnotetext{
${ }^{2}$ Las descripciones hechas corresponden a la primera y segunda fase del desarrollo. La tercera, se caracteriza por la constitución de la familia, en este estadio se observa el avance de la propiedad que a diferencia de las anteriores (tribual, estamental), esta posee la cualidad de ser privada. En este sentido, la familia de la modernidad, es considerada la primera propiedad privada que puede hallarse y con el crecimiento de la población, el aumento de las necesidades y con ello el avance del industrialismo se convierte en una relación social secundaria.
} 
que en este cuarto estadio se posicionan Marx-Engels para criticar tanto la forma de sociedad moderna, el sistema de gobierno político y la base económica imperante. Asimismo, el poder social se enmarca dentro de esta fase histórica y refiere no a las sociedades primitivas o feudales sino a la moderna.

Básicamente, según los autores, el carácter de esta cuarta etapa histórica es, en gran parte, industrial y, con base económica capitalista ${ }^{3}$. Lo que puede considerarse del industrialismo es, en principio, que su desarrollo y avance se relacionan directamente con las fuerzas productivas y la división del trabajo, lo que ocasiona cambios sustanciales en la producción ${ }^{4}$. Como segunda consideración, se destaca que el sistema económico capitalista conforma relaciones políticas y económicas entre naciones, este intercambio fue adquiriendo la forma de un mercado mundial, es decir, los intercambios transcienden los límites del mercado local para llevar adelante lo que se conoce como exportación de productos sin dejar de importar dentro del territorio nacional.

En pocas palabras, esta fase es relevante porque las condiciones de producción y relaciones sociales involuntarias que se forjan aún mantienen vigencia, es decir, (...) "determinados individuos, qué, como productores, actúan de un determinado modo, contraen entre sí relaciones sociales y políticas determinadas" (Marx-Engels, 2010, p.25).

Además, como se aclaró anteriormente, el poder social se enmarca en este contexto general. En este sentido, según Marx-Engels (2010), el poder social se define como

(...) la fuerza de producción multiplicada, que nace por obra de la cooperación de los diferentes individuos bajo la acción de la división del trabajo, se les aparece a estos individuos, por no tratarse de una cooperación voluntaria, sino natural, no como un poder propio, asociado, sino como un poder ajeno (p. 36).

De este modo, se puede agregar que tal sistema capitalista descripta por MarxEngels conforma una clase social, prominente en el siglo XIX, denominada burguesa, y

\footnotetext{
${ }^{3}$ Concentración de la riqueza en manos de unos pocos.

${ }^{4}$ Este modo de producción obliga el desplazamiento de la población del campo a la ciudad.
} 
lo novedoso es que aquella trae aparejada otra forma de organización de la sociedad, llamada la clase proletariada ${ }^{5}$. Teniendo en cuenta lo antes dicho y la cita que define lo que es el poder social, se considera que la división del trabajo -bajo el sistema capitalista- modifica la forma en que se relacionan los individuos entre sí, ya que la especialización que lo caracteriza trae consigo la monotonía y expropia al ser del poder individual, lo cual, deriva en la anulación de su creatividad y que las acciones o este poder-hacer se hallen automatizadas. A su vez, pone en contradicción los deseos particulares del individuo con los deseos generales de una sociedad. Así pues, "los actos propios del hombre se erigen ante él en un poder ajeno y hostil, que le sojuzga, en vez de ser él quien los domine" (Marx-Engels, 2010, p.34).

Como resultado de esta división de trabajo, el individuo se siente extrañado de sí mismo y de las actividades que realiza en un tiempo específico que cumple por obligación. A diferencia de las fases anteriores, en esta predomina una enajenación a nivel social y entre los individuos que cooperan o colaboran en determinados trabajos. "En efecto, a partir del momento en que comienza a dividirse el trabajo, cada cual se mueve en un determinado círculo exclusivo de actividades, que le es impuesto y del que no puede salirse" (Marx-Engels, 2010, p.34).

En tanto, el poder social, desde esta perspectiva, refiere al conjunto de fuerzas físicas e intelectuales que se manifiesta en la mutua colaboración entre los seres humanos de una determinada época. Dichas prácticas o conocimientos son traspasadas de generación en generación, modificándose -interior y exteriormente- en el transcurso de esta relación social. Aunque a simple vista aparezca establecida, se transforma en la medida en que cambie la realidad concreta, lo que supone, entre otras cuestiones, un incremento en el desarrollo de las fuerzas productivas y una nueva división de trabajo.

Lo que se elabore en esta asociación de seres, depende como se explicó, del avance de las fuerzas productivas, ya que se precisa de diferentes medios de producción (maquinarias, instrumentos, conocimientos teóricos-técnicos y la fuerza

\footnotetext{
${ }^{5}$ Así como se menciona que la clase burguesa es la que produce la clase social proletariada, cabe exponer que al mismo tiempo se constituye un nuevo sujeto, el cual, será reconocido como el sujeto trabajor o el individuo que proviene de la clase trabajadora o proletaria.
} 
física) para la relación y empleo de un producto.

Del mismo modo, este conjunto conforma la sociedad civil siendo la base por la cual se fundamentan los procesos y fenómenos económicos, su acción en conjunto, ya sea de forma consciente o inconsciente, motoriza el estado de una nación y no a la inversa. Esto puede esclarecerse con afirmaciones hechas en la Nota a la edición alemana por el autor Engels (1974):

No es el Estado el que condiciona y regula la sociedad civil, sino ésta la que condiciona y regula el Estado; de que, por tanto, la política y su historia deben explicarse partiendo de las relaciones económicas y de su desarrollo, y no a la inversa (p.7).

Para profundizar en la concepción fundamental de esta doctrina se citará lo siguiente:

La sociedad civil abarca todo el intercambio material de los individuos, en una determinada fase de desarrollo de las fuerzas productivas. Abarca toda la vida comercial e industrial de una fase y, en este sentido, trasciende de los límites del Estado y de la nación, si bien, por otra parte, tiene necesariamente que hacerse valer al exterior como nacionalidad y, vista hacia el interior, como Estado (Marx-Engels, 2010, p.38).

Hasta el momento se expuso el poder individual y poder social como formas particulares de esta noción, ya que comprende a los seres humanos en la inmersión de sus actividades esenciales. Estos dos aspectos son relevantes porque a partir de ellos deviene el poder político y el poder económico.

En principio, podríamos afirmar que desde esta perspectiva el poder político es sinónimo de Estado, tal entidad es la ejecuta y legitima prácticas y normas que hace a la organización de una sociedad. El poder del Estado posee las cualidades de ser exterior y trascendente no solamente al individuo sino a la sociedad en sí, es decir, se impone ante el poder social y ante el poder individual.

Se puede afirmar, que el poder político se impone ante el poder social, ya que es el encargado o cumple la función -junto con el poder económico- de proporcionar las condiciones materiales e intelectuales $y$, sin su intervención, no podrían 
concretarse o llevarse adelante los modos de producción. Sumado a esto, establecen relaciones sociales en el mercado mundial o entre otras naciones que, de alguna manera, alteran o modifican toda cooperación mutua o toda fuerza de producción ${ }^{6}$.

Dado que el poder político contiene los bienes materiales para respaldar la reproducción de ideas que imperan puede instituir un conocimiento que adquiere un carácter colectivo ${ }^{7}$.

Retomando un poco la cuestión de sus funciones, una de las razones por las cuales cobra sentido su cualidad representativa, es la conciliación que debe efectuar entre la contradicción de los intereses, que como hemos visto existe tanto a nivel individual como en relación al interés de la sociedad. Sin embargo, esta especie de finalidad que tiene el Estado es dilucidada por Marx-Engels (2010) al concebir que "en realidad es una forma propia e independiente, separada de los reales intereses particulares y colectivos $\mathrm{y}$, al mismo tiempo, como una comunidad ilusoria, pero siempre sobre la base real de los vínculos existentes" (p.35).

Como se explicitó anteriormente, en el poder del estado o político se concentra y se distribuye -de modo desigual- los bienes materiales. Debido a esta concentración de bienes materiales se considera que detenta el poder, y que sustenta la división de trabajo de las clases dominantes, como es el intelectual y físico. Como puede observarse en la siguiente cita: "Las ideas de la clase dominante son las ideas dominantes en cada época; o, dicho en otros términos la clase que ejerce el poder material dominante en la sociedad es, al mismo tiempo, su poder espiritual dominante" (Marx-Engels, 2010, p.51).

Frente a la especie de omnipotencia que representa el Estado (ya que domina y controla según se profundiza la división de trabajo, se acrecientan las fuerzas de producción y destina los bienes materiales a las ideas funcionales al gobierno de turno

\footnotetext{
${ }^{6}$ Se remarca, nuevamente, que las posibles razones para esta configuración, son progreso de las fuerzas productivas o cambios en la división de trabajo.

${ }^{7}$ Se piensa que, dentro de este poder político, se encuentran mecanismos o subdivisiones que funcionan dentro de este poder y actúan sobre la realidad concreta, a saber: poder normativo -formas de ser y actuar éticas que se instauran e implican obediencia, ejemplo, relación asimétrica en entre los padres e hijos, empleados y empleador.

Poder discursivo y poder ideológico -conjunto de ideas que conforman un conocimiento esperado por algún sector de la sociedad, legitima un poder- ejemplo, la prensa y los ideólogos.
} 
que impera en la sociedad), Marx-Engels (2010) proponen: "Y se desprende, asimismo, que toda clase que aspire a implantar su dominación (...) tiene que empezar conquistando el poder político, para poder presentar su interés como el interés general, cosa a que en el primer momento se ve obligada" ( p.35).

En pocas palabras para Marx-Engels, ya que este tipo de poder estatal o político, es comprendido en un sentido negativo, si hay una política o estado de gobierno que debe instituirse es la denominada comunista. Esta forma de política revolucionaria, pregona la abolición del Estado y considera que el poder debe ser transferido a la sociedad civil quien es, en este caso, la que impulsa el comercio y otorga estabilidad. Por último, a la luz de estas consideraciones se puede decir que

(...) los bienes materiales serian propiedad de la sociedad y no habría que aceptar la propiedad privada, en cuanto lo que existe es por naturaleza de la humanidad en sí. Nosotros llamamos comunismo al movimiento real que anula y supera al estado de cosas actual (Marx-Engels, 2010, p.37).

Así pues, como última acepción a la noción de poder se encuentra el poder económico, del cual, conviene advertir que, al igual que el poder individual, frente a este aspecto del poder no se posee una teoría explicita; sin embargo, se intentará brindar ciertas consideraciones halladas en germen.

En líneas generales, cabe mencionar, que los autores centran su concepción histórico-materialista en relación a los fenómenos y competencias económicas. Este dato es relevante, ya que nos muestra cómo es posible concebir la realidad concreta, lo que el individuo es, las relaciones sociales y el estado de un gobierno, a partir, de una dimensión económica.

Lo que no implica la reducción de distintas corrientes de pensamientos a una explicación netamente económica, sino que se torna necesaria su incorporación, ya que de por sí, es un aspecto fundamental en los procesos y desarrollos del mundo real y natural, por el simple hecho de que predomina una "trabazón existente entre la organización social, política y la producción" (Marx-Engels, 2010, p.25); y porque es empíricamente comprobable que la economía es el núcleo por el cual, se reafirma la posición política de un Estado determinado, se fortalecen los lazos o relaciones 
sociales involuntarias mediante el comercio, y la supervivencia material del individuo.

Dicho esto, el poder económico, en la Ideología Alemana, se circunscribe bajo el sistema capitalista, antes nombrado. Por ende, se puede afirmar, que es equivalente al mercado mundial, funciona como regulador del comercio y las relaciones sociales, y por último, como medio para el progreso de las fuerzas productivas. Para esclarecer lo expuesto hasta el momento citaremos lo siguiente

es, evidentemente, un hecho empírico el que los individuos concretos, al extenderse sus actividades hasta un plano histórico-universal, se ven cada vez más sojuzgados bajo un poder extraño a ellos (...), poder que adquiere un carácter cada vez más de masa y se revela en última instancia como el mercado mundial (MarxEngels, 2010, p.39).

En consonancia, con la cita, debido al carácter funcional, histórico e instrumental que representa el poder económico frente a los diversos poderes, se sostiene que este proporciona movimiento y activa las acciones productivas, ya que, aquello que realizan los individuos en una determinada época está en función del estado de intercambio comercial del mundo y las políticas establecidas ${ }^{8}$.

En palabra de los autores

La industria y el comercio, la producción y el intercambio de las necesidades de la vida se condicionan por su parte y se hallan, a su vez, condicionadas en cuanto al modo de funcionar por la distribución, por la organización de las diversas clases sociales (Marx-Engels, 2010, p.47).

El fragmento citado nos permite introducir la cuestión de las clases sociales desde este terreno. Como se esbozó, con anterioridad, en el siglo XIX a causa de la transición del sistema feudal al sistema burgués se produjeron dos clases sociales antagónicas denominadas: clase burguesa o capitalista y la clase proletariada.

En el apartado sobre el poder social, aquellas solo fueron referidas como dos tipos de organización de organización social constituidas en la cuarta fase del

\footnotetext{
${ }^{8}$ tanto la economía como la sociedad civil, son la base que sostienen y de la cual dependen los lazos y la respectiva vida de los seres humanos.
} 
Abril 2021.

ISSN 2344-9934

desarrollo histórico. No obstante, en este punto, podemos alegar que cada clase social es antagónica u opuesta por su disposición económica, es decir, el poder económico, adquisitivo o capital que posea determinada clase los diferencia.

Siendo así que, por un lado, la clase capitalista se caracteriza por poseer, en gran parte, los bienes materiales y el manejo de las materias primas e instrumentos necesarios para la producción, en otras palabras, quienes integran esta clase social empresarios, comerciantes-son poseedores de los medios de producción social; y retomando un poco la última cita, esta clase social es la que condiciona la industria, el comercio y el intercambio de la vida, y por consiguiente el salario -precarizado- de la clase obrera.

Por otro lado, la clase proletaria, en esta concepción, producto de la clase burguesa es denominada clase desposeída, ya que desprovisto de todo medio y bienes materiales para subsistir por sí mismo debe vender su fuerza física de trabajo con arreglo a largas horas y bajo sueldo.

Continuando con la temática se transcribirá una parte de la obra en la que Marx-Engels (2010) aluden a la acción del Estado que pretenden abolir en relación al poder económico y las clases sociales

Para que se convierta en un poder "insoportable", es decir, en un poder contra el que hay que sublevarse, es necesario que engendre a una masa de la humanidad como absolutamente "desposeída" y, a la par con ello, en contradicción con un mundo existente de riquezas y culturas (p.36).

En definitiva, el poder económico interviene directa e indirectamente y engloba las diversas clases de poder, esto quiere decir, que el poder económico es la fuente de, la cual, derivan todas las demás clases de poder, es la base y concreción de cada una.

\section{Reparo en interrogantes no explicitados.}

Llegado a este punto, es preciso indicar, que la pretensión del trabajo fue mostrar la variedad de poderes prominentes en la obra y, a su vez, responder los interrogantes propuestos; por lo tanto, nos encontramos en condiciones de alegar que cada forma de poder difiere por su grado de consciencia, condiciones materiales y 
nivel de relación contraída. Asimismo, todo ser humano particular como la humanidad en general, posee modos de ejercer el poder -que parte en primer lugar, desde lo más básico como la acción de producir, hasta la complejización de esta, por las relaciones sociales que se forjan localmente o por fuera del lugar residente, la división de trabajo, las condiciones y los medios con los que se produce.-

Sin embargo, que el poder sea inherente a las cuestiones sociales y a la realidad material, como hemos visto, esto no significa que prevalezca un ejercicio, actitud o posición igualitaria y equitativa ${ }^{9}$. Justamente por esta cualidad de poder diversificado, se procura propiciar relaciones y clases asimétricas u opuestas y desposeer a un sector para beneficiar o privilegiar a otro.

Así pues, que el sujeto y la sociedad juzguen que el poder solo pertenece a los poderes generales, como lo son el político y económico, responde a dos posibles causas o razones. La primera es la naturaleza e implementación del sistema capitalista, que integra dimensiones políticas y económicas del cual, deriva (entre otras cuestiones) la alienación del género humano, del trabajo, del producto trabajado y del individuo mismo. En tanto, la alienación como efecto de este sistema económicopolítico opera

situado al margen de ellos, que no saben de dónde procede ni a dónde se dirige y que, por tanto, no pueden ya dominar, sino que recorre, por el contrario, una serie de fases y etapas de desarrollo peculiar e independiente de la voluntad y de los actos de los hombres y que incluso dirige esta voluntad y estos actos (Marx-Engels, 2010, p.36).

La segunda razón es la falsa conciencia que conforma el sujeto sobre la realidad misma, ya que este, ocupado en sus actividades productivas, más bien, siendo explotado, asume una posición pasiva dentro del plano gnoseológico. Dicho de otra forma, el sujeto sólo conoce lo que esté dentro del trabajo forzado, por lo que la propia actividad productiva le impide tomar distancia de la producción y poner bajo crítica la multiplicidad de ideas que circundan y fundamentan un tipo de realidad y

\footnotetext{
${ }^{9}$ Cuando se refiere al ejercicio igualitario se comprende que engloba toda práctica en donde los intercambios comerciales se lleven a cabo sin ninguna represión y, a la vez, sea posible gozar de los resultados y oportunidades de aquellas relaciones sociales y comerciales.
} 
Abril 2021.

ISSN 2344-9934

conocimiento aparente.

En consecuencia, es comprensible que el sujeto se halle obnubilado teniendo por concepciones ideas que encubren la realidad y persiguen intereses determinados, e identifique al Estado como la única y verdadera expresión de poder existente, por dar un ejemplo. Lo dicho, es descripto por Marx-Engels (2010) de la siguiente manera:

Una parte de esta clase se revela como la que da sus pensadores (los ideólogos conceptivos activos de dicha clase, que hacen del crear la ilusión, esta clase acerca de sí misma su rama de alimentación fundamental), mientras que los demás adoptan ante estas ideas e ilusiones una actitud más bien pasiva y receptiva, ya que son en realidad los miembros activos de esta clase y disponen de poco tiempo para formarse ilusiones e ideas acerca de sí mismos. (p.51).

De esta manera, afirmamos que el sistema capitalista, como superestructura y la falsa conciencia como ideología, crean un poder alienante y determinan las condiciones de posibilidad de conocimiento del sujeto y la sociedad.

\section{Definición de poder.}

Dado el recorrido realizado hasta el momento daremos una definición general del término poder.

Entendemos por poder, de manera particular, al sistema de relaciones materiales e históricas- y fuerzas -físicas e intelectuales- que entablan los individuos entre sí, y en la sociedad misma. Estas relaciones se originan dentro de un determinado territorio o trascendiendo dichos límites.

La interacción no es comprendida desde un sentido gnoseológico, es decir, en donde el resultado de aquella relación sea producto por el conocimiento que el sujeto se ha figurado debido a las impresiones que percibe de la realidad externa y las fuerzas (instintivas, emocional o racional) que experimente en la realidad interna; más bien, se lo enmarca en un plano ontológico, es decir, existe y prevalece dentro de la naturaleza y la realidad concreta.

El poder existe en cualquier actividad que implique la participación práctica, 
activa y actuante de los sujetos, aunque esta relación material no acaba en el individuo, sino que adquiere su sentido real en la sociedad y el trabajo, ya que se pone de manifiesto y se concretiza dicha praxis.

No obstante, se observa que la propiedad "cuya forma inicial se contiene ya en la familia" (Marx-Engels, 2010, p.33), es considerada una relación social (primaria o secundaria según las fases), en donde es posible hallar una división del trabajo y la reproducción de las normas sociales establecidas en el contexto.

De manera general, el poder es definido como sistema de fuerzas instituidas que se imponen en la sociedad, ya que detrás de cada estructura normativa, institucional y competencia del mercado, funciona un poder económico o político que interviene en los procesos sociales para forjar una forma de organización, coaccionar o componer un tipo de relación social-económico.

El despliegue del poder está íntimamente vinculado con el desarrollo de la propiedad privada y, para el tercer y cuarto momento de las fases productivas del ser humano, con la división del trabajo que, para esas instancias, como puede notarse, está ampliamente instaurada. Con el avance de la propiedad y la división de trabajo se acrecienta el poder adquisitivo y control del poder político y económico.

\section{Conclusión.}

La definición que se intentó reconstruir retoma aspectos centrales de cada acepción explicada. Lo que caracteriza al poder es sus múltiples dimensiones, una fuerza que impulsa a concretar las actividades que hacen funcionar o transformar la realidad existente y material, y aporta movimiento a la historia misma del ser.

Se expresa desde la propiedad privada y pública, como en el interior del sujeto y al exterior de éste. Es mutable y mudable, ya que, su condición inherente es ser histórico. Se puede afirmar que el poder es relativo, porque depende de qué o quien ejerce un tipo de poder y desde qué posición.

Consideramos que el termino es transversal porque trastoca cada ámbito del ser humano, desde la relación práctica que efectúa el individuo, las relaciones sociales 
que se entablan por necesidad, hasta las tensiones y luchas que prevalecen en los distintos mecanismos de la superestructura que engloba los estadios, tales como, la cultura, política, procesos económicos y ámbito jurídico.

Existe un poder que es alienante porque predominan múltiples poderes, normas, leyes y moralidades que funcionan y actúan de manera sutil o de forma explícita en la organización social como en el individuo. Se tornan efectivas estas acciones formales hasta su normalización cuando el individuo o sociedad recepciona de modo pasivo y sin adjudicar críticas.

Lo interesante de esta concepción es que logró mediante la dialéctica materialista y un profundo criticismo, evidenciar de dónde proviene y cuál es el resultado de dichos vínculos alienantes. Para esto, llegaron a expresar que la sensación de extrañeza, es decir, la enajenación se producía, en un primer momento, entre el ser humano y la naturaleza. En las fases siguientes entre el individuo y la sociedad, y por último, entre compañeros de trabajo y la producción misma.

Como consecuencia de esta profundización y amplitud de las relaciones se propició un desconocimiento sobre la existencia consciente de un poder inherente al ser y sobre otro poder que impulsa el desarrollo económico y político, como lo es el poder social o sociedad civil.

Si bien, se procuró aportar una interpretación sobre las nociones de poder en Marx-Engels, es preciso señalar algunas consideraciones.

Así pues, si el objetivo primordial de Marx-Engels al escribir la Ideología Alemana radica en derribar la falsa conciencia ${ }^{10}$, este objetivo no se cumple en sentido estricto, porque al no aportar una teoría o no sistematizar la noción que nos acucia, la cuestión queda tácita y sobreentendida, dejando un margen que posibilita que el termino se reduzca a una mera y simple mención o en otros casos se exponga algún análisis considerando solamente un aspecto. Tal es el caso, de quienes han hecho énfasis en identificar y clasificar el poder material e histórico mencionado por los autores como un poder cosificado, lo que implica un sistema cerrado que solo puede ser estudiado a partir de los objetos de la realidad.

\footnotetext{
${ }^{10}$ la cual, se instala mediante mecanismos funcionales a determinadas clases que poseen los bienes materiales para sostener la reproducción de ideologías e instaurar un tipo de poder
} 
En consecuencia, se produce una falsa conciencia, es decir, una concepción errónea, una idea y conocimiento que no acompaña los principios que persiguen en la obra tratada y, como resultado carece de sentido concebir un poder con terminologías tan versátiles.

Entonces, si Marx pretendía desestabilizar lo establecido debía criticar las ideas en torno a lo concebido como poder instituido y constituyente, así como las diversas categorías que a lo largo de la obra son enumeradas.

Por otro lado, se observa otra deficiencia dentro de este tema en particular, ya que uno de los objetivos para la fundamentación de su denominada Filosofía Positiva pretende conciliar a la teoría con la praxis y viceversa, en post de transformar la realidad concreta. Y como omite profundizar y refutar sobre el poder no reafirma su doctrina filosófica, más bien, pareciera que solo se aboca a aportar datos empíricos y ofrecer una crítica lo más acertada posible.

\section{Bibliografía:}

Lenin, V.I. (1947). Marx, Engels y el Marxismo. Moscú: Del Instituto Marx-Engels-Lenin.

Marx, K. - Engels. F. (1974). La ideología alemana. Montevideo y Barcelona: Pueblos Unidos y Grijalbo. Nota a la edición alemana.

Marx, K. - Engels. F. (2010). La ideología alemana (I). En: Marx, K. La ideología alemana (I) y otros escritos filosóficos. Buenos Aires: Losada. 